\title{
Bir Belediyede Görev Yapan Sağlık Çalışanlarının İş Doyumu Algılarının Belirlenmesi: Nitel Bir Araştırma
}

DOI: 10.26466/opus.789148

\author{
*Türkan Aşcıoğlu - ** Mehtap Kızılkaya \\ *Uzm. Hemşire, İSKİ Sağlık ve İş Güvenliği Şube Müdürlüğü, İstanbul/Türkiye \\ E-posta: turkanascioglu@gmail.com \\ ORCID: $0000-0003-0133-7281$ \\ ** Dr. Öğr. Üyesi, Aydın Adnan Menderes Üniversitesi, Hemşirelik Fakültesi, Aydın/ Türkiye \\ E-posta: mehtap.kizilkaya@adu.edu.tr \\ ORCID: $\quad \underline{0000-0002-4000-8926}$
}

\section{Öz}

İş, bireylerin yaşamın devam ettirmelerinde gerekli olan ekonomik kazanç sağlama yolu olduğu için temel bir işleve sahiptir. Çalışanlarm işe yönelik tutumları olumlu ise iş doyumundan söz edilebilir. İ̧̧ doyumu yaşamın genelinden alınan doyumla ilintili olduğu için oldukça önemlidir. Bu çalışma, İstanbul'da bir belediyede görev yapan sağllk çalışanlarının iş doyumuna yönelik görüşlerini kendi algıladıkları doğrultuda belirlemek amacıyla yapılmıştır. Araştırmanın evrenini, ilgili belediyenin sağ̆lk hizmeti veren birimindeki 47 sağlık çalışanı, örneklemini ise çalışmaya katılmayı gönüllü olarak kabul eden 35 sağllk çalışanı oluşturmuştur. Sağlık çalışanlarına kişisel bilgi formu ve görüşme formu uygulanmıştır. Veriler, 1 Ocak- 28 Şubat 2018 tarihleri arasında, nitel araştırma yöntemlerinden yar yapılandırılmış görüşme tekniği kullanılarak toplanmıştır. Veriler analiz edilmiş, temalar oluşturulmuş, araştırma sonuçlarına göre literatür taraması yapılarak yorumlanmıştır. Sağlık personellerinin

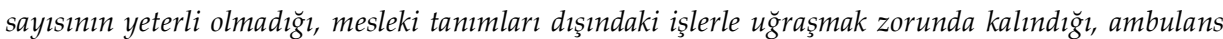
personeli ve revir personelinin ayrı olmaması nedeniyle iş yükünün fazla olduğu, mesleki sinırların netleşmesi gerektiği, birim içi sosyo-kültürel faaliyetlerin yetersiz olduğu gibi bulgulara ulaşılmıştır. Sağlık personellerinin kurum içindeki sorunların giderilmesinde, yöneticilerin daha sık toplantılar yaparak kendileriyle görüşmelerini istedikleri saptanmıştır. Çalışma sonucunda ilgili kurumda çalışan sağlık personellerinin iş doyumunu arttırmak için daha kapsamlı çalışmaların yapılması önerilmiştir.

Anahtar Kelimeler: sağlık çalışanı, iş doyumu, belediye, nitel araştırma 


\title{
Determination of Job Satisfaction Perceptions of Healthcare Professionals Working in a Municipality: A Qualitative Research
}

\begin{abstract}
Work has a basic function as it is the way of gaining economic gain that is necessary for individuals to survive. If the employees' attitudes towards the job are positive, then job satisfaction can be mentioned. Job satisfaction is very important as it is related to satisfaction from the general life. This study was conducted to determine the job satisfaction of health workers in a municipality in İstanbul from their perception. The population for this research consists of 47 health workers that provide service to the municipality. There search sample consists of the 35 health workers who agreed voluntarily to join. The nurses were given the personal information form and interview form. The data was collected between 1 January 2018-28 Febuary 2018 using semi-structured interview technics from qualitative research methods. The data was analyzed, themes were formed, and commentary was made afterconducting a literature review according to the results of the study. Insufficiency of the number of health workers, having to do tasks that are not included in their job definition, too much work load due to not having a separation between infirmaryand ambulance personnel, the necessity of having clear job boundaries, and insufficient socio-cultural activities in the unitwerefound. Another finding was that the health personnel wanted managers to discuss with them through more meetings to hand leissues with in the organization. According to the results of the study, more comprehensive studies must be conducted to increase the job satisfaction of the health personnel.
\end{abstract}

Keywords: health worker, job satisfaction, municipality, qualitative research 


\section{Giriş}

İş; "insanların yaşamlarını devam ettirebilmek için harcadikları zihinsel ve bedensel uğraşların tamamı" olarak tanımlanmıştır (Düzova, 2015). İnsan yaşamında çalışmak ve bir işe sahip olmak önemli bir yer işgal etmektedir. Çalı̧̧ma yaşamı, bireyin yaşamını devam ettirebilmesi için maddi kaynak sağlamasinın yanı sıra bireyin, toplumda belli bir yer ve rol sahibi olabilmesi ve toplumsal saygınlık elde etmesi içinde gerekli olan temel toplumsal kurumlardan biridir. Bireylerin işlerinden elde ettikleri doyum bireysel ve kurumsal açıdan önemlidir. Birey-iş ilişkisinde olumlu ya da olumsuz tutumlar, çallşanın işinden elde edeceği doyumu etkilemektedir (Kaya, Bilgin, 2015). Çalışan insan, gününün büyük kısmını iş ortamında geçirmekte olduğundan fiziksel, ruhsal ve sosyal gereksinimlerinin iş ortamında karşılanmasını beklemektedir (Demir, 2016). Eğinli'nin (2009) aktardığına göre, Barutçugil iş doyumunu "bir çalı̧anın yaptığı işin ve elde ettiklerinin ihtiyaçlarıla ve kişisel değer yargilarıla örtüştüğünü veya örtüşmesine olanak sağladığın fark etmesi sonucu yaşadığı bir duygu" olarak açıklamaktadır (Eğinli, 2009). İş doyumunu etkileyen bireysel faktörler; yaş, cinsiyet, medeni durum, eğitim, çocuk sahibi olma durumu, sosyo-kültürel çevre, değer yargıları, inançlar, kişilik, zeka, meslekte geçen süre, çalışmakta olduğu işini seçme nedeni, işin birey için anlamı, mesleki gelişme firsatı, bireyin beklentileri, işten ayrılma isteği, işin kişiliği ile uyumu, genel yaşam doyumu, stresle baş edebilme durumu ve genel sağlık durumu olarak ifade edilmektedir (Taş, 2010). İş doyumunu etkileyen çevresel ve örgütsel faktörler ise; işin niteliği, ücret-maaş, örgütsel ilişkiler, iş güvenliğinin olması, çalısma koşulları, yönetim biçimi, örgütsel konum, kararlara katılma, yetki ve sorumluluk devri, örgütün sağladığ 1 yükselme-gelişme olanakları, çalışma arkadaşlarıyla ilişkiler, görevin ayrıntıları, denetim, iş yükü, ek olanaklar, otomasyon ve performans ölçümleridir (Akbaş, 2011). Doğrudan insana hizmet veren meslek gruplarında, tükenmişlik önemli sonuçlar doğurabilmektedir. Derin'in (2007) aktardığına göre, Aştı́nın yaptığı çalışmada işlerinde doyumsuzluk yaşayan bireylerin aynı zamanda çeşitli psikosomatik sorunlar yaşadığı ve yapılan çalışmalarda yorgunluk, nefes darlığı, çarpıntı, baş ağrısı, terleme, iştahsızlık, hazımsızlık ve bulantı hissi gibi yakınmaların iş doyumsuzluğu ile ilişkili olduğu belirlenmiştir (Derin, 2007). Sağlık hizmeti, çok sayıda farklı meslek grubundan oluşan multidisipliner bir hizmettir. 
Sağlık profesyonelleri toplumun sağlığının korunması ve sürdürülmesinde doğrudan görev aldıkları, yoğun çalışma şartları ile mücadele ettikleri ve özverili davranmaları gerektiği için iş doyumu diğer meslek gruplarına göre daha fazla önem taşıdığı bilinmektedir (Aytekin, 2014). Sağlık çalışanları çalışma şartlarından memnun ve iş doyumları yüksek ise kaliteli bakım hizmeti sunmaları kaçınılmazdır (Toker, 2013). Belediyelerde işyeri hekimliği, kurum hekimliği gibi birinci basamak sağlık hizmeti verilmektedir. Bu çalışma hastane dışında çalışan sağlık çalışanlarının yaşadıklarını belirlemek açısından önem arz etmektedir. Bu çalışmanın amacl; bir belediyede görev yapan sağlık çalışanlarının iş doyumuna yönelik görüşlerini kendi algıladıkları doğrultuda belirlemektir.

\section{Yöntem}

\section{Araştırmanın Modeli}

Nitel araştırma yöntemlerinden "tek durumlu örnek olay çalışması" ile desenlenerek gerçekleştirilen çalışma, İstanbul'da bir belediyede 1 Ocak - 28 Şubat 2018 tarihleri arasında gerçekleştirilmiştir. Araştırmanın evrenini, ilgili belediyenin sağlık hizmeti veren biriminde çalışan 47 sağlık çalışanı, araştırmanın örneklemini ise çalışmaya katılmayı gönüllü olarak kabul eden 35 sağlık çalışanı oluşturmuştur.

\section{Veri Toplama Araçlar}

Araştırmanın veri toplama işlemine başlamadan önce, katılımcılara araştırmanın amacına yönelik kapsamlı olarak bilgilendirme yapılmıştır. Bu bilgilendirmeye olumlu cevap veren ve çalışmaya gönüllü olarak katılmayı kabul eden sağlık çalışanlarının verileri Sosyo- demografik özelliklerin yer aldığ 1 "Kişisel Bilgi Formu" ve "Yarı Yapılandırılmış Soru Formu" kullanılarak elde edilmiştir.

Kişisel Bilgi Formu; Bu form katılımcıların cinsiyeti, yaşı, eğitim duru$\mathrm{mu}$, medeni durumu, çocuk sahibi olma durumu, mesleği, meslekte çalışma yılı, gelir düzeyi ve haftalık çalışma süresini içeren 14 sorudan oluşmaktadir.

Yarı Yapılandırılmış Soru Formu; Yarı yapılandırılmış soru formu, sağlık çalışanlarının iş doyumu kavramına dair görüşlerini, çalışma koşullarının fiziksel, ruhsal ve sosyal sağlıklarını nasıl etkilediğine yönelik algılarını ve 
kurumsal planlama önerilerini ortaya koymak amaciyla 6 adet açık uçlu sorudan oluşmuştur.

\section{Verilerin Toplanması ve Değerlendirilmesi}

Veriler, nitel araştırma yöntemlerinden yarı yapılandırılmış görüşme tekniği kullanılarak toplanmıştır. Veriler toplandıktan sonra verilerin ham dökümü bilgisayara araştırmacı tarafından yazılmıştır. Elde edilen verilerin analizinde, tümevarımsal içerik analizi tekniği kullanılmıştır. İçerik analizi birbirine benzeyen verileri belirli kavramlar ve temalar çerçevesinde bir araya getirmek ve bunları okuyucunun anlayabileceği bir biçimde düzenleyerek yorumlamaktır (Yıldırım ve Şimşek, 2008). Verilerin analizinde ham veriler satır satır okuma tekniği ile birkaç kez okunmuş, açık kodlama yoluyla anlamlı görülen her bir kelime kodlanmış daha sonra tematik kodlama yapılmıştır. Kodlardan kategorilere ve daha sonra da temalara ulaşılmıştır. Analiz için veriler en küçük anlam birimleri dikkate alınarak kodlanmıştır (açık kodlama), belirli bir anlam etrafinda birbiri ile ilgili kodlar bir araya getirilerek (dikey kodlama) dikey kodlamada belirlenen çekirdek kategoriler birleştirilerek temalar oluşturulmuştur (seçici kodlama) ve yorumlanarak anlamlı hale getirilmiştir. Daha sonra veriler organize edilip, yorumlanarak rapor haline getirilmiştir.

\section{Araştırmanın Etik Boyutu}

Çalışma için kurum izni ve Etik Kurulu onayı alınmıştır (Etik Kurul Onayı: 08.11.2017 tarihli toplantıda Karar No:88). Çalışma, Helsinki Bildirgesi ilkelerine bağll kalarak yürütülmüsstür.

\section{Bulgular}

Katılımcların 19'u kadın ve 16 'sı erkektir. Araştırmaya katılanların $\% 68,6$ 'sının ( $\mathrm{n}=24)$ 41ve üzeri yaş aralığında \%54,2'sinin ( $\mathrm{n}=19)$ kadın, $\% 85,7^{\prime} \operatorname{sinin}(n=30)$ evli, \%91,4'ünün ( $\left.\mathrm{n}=32\right)$ çocuk sahibi, \%60'ının ( $\left.\mathrm{n}=21\right)$ lisans mezunu olduğu, \%62.9'unun ( $\mathrm{n}=22) 16$ ve üzeri yıldır çalıştıkları görülmektedir (Tablo 1). 
Tablo 1. Katılımcıların sosyo- demografik özellikleri

\begin{tabular}{|c|c|c|}
\hline Özellikler & $\mathrm{n}$ & $\%$ \\
\hline \multicolumn{3}{|l|}{ Cinsiyet } \\
\hline Kadın & 19 & 54.2 \\
\hline Erkek & 16 & 45.7 \\
\hline \multicolumn{3}{|l|}{ Eğitim Durumu } \\
\hline Lise & 8 & 22.8 \\
\hline Ön Lisans & 4 & 11.4 \\
\hline Lisans & 21 & 60 \\
\hline Yüksek Lisans & 2 & 5.8 \\
\hline \multicolumn{3}{|l|}{ Medeni Durumu } \\
\hline Evli & 30 & 85.7 \\
\hline Bekar & 5 & 14.3 \\
\hline \multicolumn{3}{|l|}{ Çocuk Varlığı } \\
\hline Var & 32 & 91.4 \\
\hline Yok & 3 & 8.6 \\
\hline \multicolumn{3}{|l|}{ Yaş } \\
\hline $21-30$ & 2 & 5.7 \\
\hline $31-40$ & 9 & 25.7 \\
\hline $41-50$ & 24 & 68.6 \\
\hline \multicolumn{3}{|l|}{ Mesleği } \\
\hline Hemşire & 13 & 37 \\
\hline Sağlık Memuru & 1 & 2.9 \\
\hline ATT & 3 & 8.6 \\
\hline Hekim & 7 & 20 \\
\hline Diş Hekimi & 1 & 2.9 \\
\hline Eczac1 & 1 & 2.9 \\
\hline Ambulans Şoförü & 9 & 25.7 \\
\hline \multicolumn{3}{|c|}{ Meslekte Çalışma Yılı } \\
\hline $1-9$ & 4 & 11.4 \\
\hline $10-19$ & 22 & 62.9 \\
\hline $20-29$ & 9 & 25.7 \\
\hline
\end{tabular}

Bir belediyede görev yapan sağlık çalışanlarının iş doyumuna yönelik görüşlerini kendi algıladıkları doğrultuda belirlemek amacıyla gerçekleştirilen bu durum çalışmasında, görüşme soruları ile elde edilen veriler, temalar biçiminde bulgulara dönüştürülerek verilmiştir. Araştırmanın çalışma grubunu oluşturan sağlık çalışanlarına, iş doyumu kavramıyla ilgili olarak ne düşündükleri sorulmuş ve yanıtları sonucunda bazı kategorilere ulaşılmıştır. Sağlık çalışanlarının üçte birinden fazlası $(n=14)$ iş doyumunu mutlu huzurlu olmak şeklinde ifade etmişlerdir. Katılımcıların dörtte biri $(n=9)$ iş doyumunu maddi- manevi tatmin olarak düşündüklerini belirtmişlerdir.

Çalışma grubunu oluşturan personelin üçte biri $(n=12)$ işini severek yapmanın iş doyumu anlamına geldiğini vurgulamışlardır. 


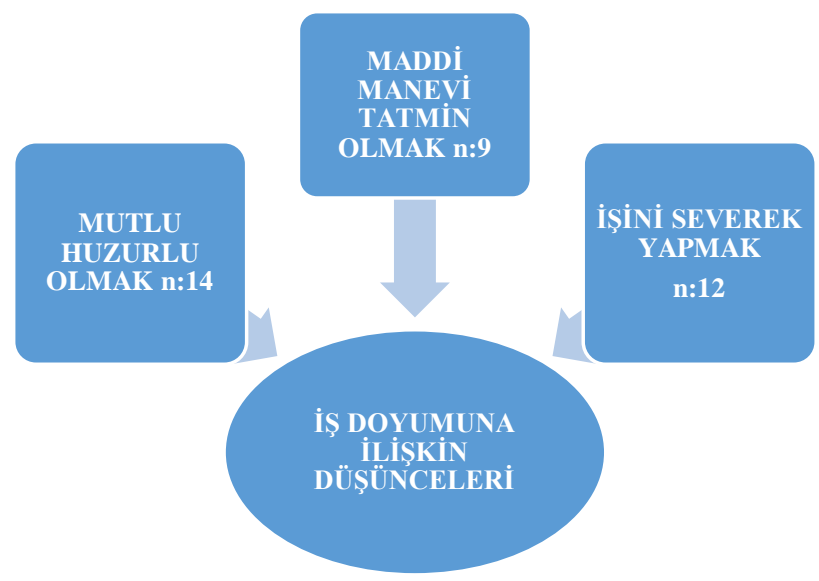

Bu konudaki bazı katılımcı görüşleri şu şekildedir;

- "İş doyumu işyerinde mutlu ve huzurlu olmaktır" (katılımo 1)

- "Maddi manevi açıdan tatmin olmaktır"(katılımo 2)

- "İsini severek yapmaktır bence"(katılımcı 25)

Katılımcların iş doyumlarının nelerden etkilediği sorulduğunda, sağlık çalışanlarının yarısından fazlası $(n=21)$ iş doyumunun çalışma ortamının fiziksel şartlarından etkilendiğini düşündüklerini belirtmişlerdir. Sağlık çalışanlarının üçte biri $(n=12)$ iş arkadaşlarının iş doyumunu etkilediğini ifade etmişlerdir. Çalışma grubunu oluşturan sağlık çalışanlarının hemen hemen yarısına yakını $(n=15)$ yöneticilerin motivasyona yönelik tutumlarının iş doyumunu etkilediğini iletmişlerdir. Sekiz katılımcı iş doyumunu aldıkları maaş-ücretin etkilediğini düşündüklerini, dört katılımcı ise rol, görev ve sınırların net olmayışının iş doyumunu etkileyebileceğini vurgulamışlardır. Katılımcıların beşte biri $(n=7)$ çalışanın ruhsal ve fiziksel bir hastalığının olmasının iş doyumunu etkileyebileceğini ifade etmişlerdir. Sağlık çalışanlarına çalışma koşullarının fiziksel sağlıklarını nasıl etkilediği sorulduğunda, yarısından fazlası $(n=18)$ bel ağrısı yaşadıklarını belirtmişlerdir. Katılımcıların yarısına yakını $(n=14)$ bacak ağrısı olduğunu ifade etmişlerdir. Çalışmaya katılan sağlık çalışanlarının dörtte birinden fazlası $(n=10)$ bacak ve varis ağrısı deneyimini iletmişlerdir. Katılımcıların beşte biri $(n=7)$ yorgunluk şikayetinden söz ederken, bir katılımcı ise çalışma koşullarının mide şikayetlerine neden olabildiğini aktarmaktadır. Çalışma koşulla- 
rının ruhsal sağlığı nasıl etkilediğine yönelik soruya araştırmaya katılan sağlık çalışanlarının yarısı ( $\mathrm{n}=17)$ stres cevabını verirken, katılımcıların yaklaşık beşte biri $(n=6)$ sinirlilik diye ifade etmişlerdir. Sağlık çalışanlarından beşi ruhsal yorgunluk diye aktarmışlardır. İki katılımcı ruhsal gerginliğe bağlı uyku problemini iletirken, hizmet verdikleri hastalara yönelik "fazla empati yapmak" sonucu üzüntü yaşadığını belirten katılımcılar bulunmaktadır (katılımcı 10,11,16). Bir sağlık çalışanı da öfke patlamasından söz etmektedir. Sağlık çalışanlarının çalışma koşullarının sosyal yaşamı nasıl etkilediğine dair düşüncelerinin neler olduğu sorulduğunda, araştırmaya katılanların yarısından fazlası $(\mathrm{n}=22)$ çalışma koşullarının sosyal yaşamlarını etkilemediğini ifade ederken bunu "profesyonel simırları korumak lazım", "eve iş götürmem"(katılımcı 1,2,3,4,5,6,19,20,23,24,32,34,35) diye aç1klamaktadırlar. Sağlık çalışanlarının üçte biri ise ( $\mathrm{n}=11$ ) sosyal faaliyetlere zaman ayıramadıklarını belirtmişlerdir.

- "Aileme arkadaşlarıma ayırdığım zaman azalıyor, kültür ve sanat etkinliklerim azaldı" (katıllimcr 21)

- "Sosyal aktivitelere zaman yok" (katılıma 17, 28, 30)

- "Yorgunluğa bağhl sosyal çekilmem var" (katıllmcı 18)

Katılımcılara daha iyi bir çalışma ortamı için önerileri sorulmuş ve cevapları sonucunda bazı kategorilere ulaşılmıştır. Bu kategoriler fiziksel koşullarda iyileşme, çalışma koşullarında iyileşme, sosyal planlamalara yönelik iyileşme ve eğitim faaliyetlerine yönelik iyileşme şeklindedir. Sağlık çalışanlarının yaklaşık altıda biri $(n=5)$ fiziksel koşullarda iyileşmenin sağlanması gerektiğini ifade etmişlerdir. Çalışma koşullarında iyileşme kategorisine ilişkin katılımcıların yaklaşık üçte biri $(\mathrm{n}=10)$ "görev tanımları net olmalı" diye belirtmişlerdir. Araştırmaya katılan sağlık çalışanlarının yaklaşık beşte biri $(n=6)$ personel sayısının ve malzeme ihtiyacının giderilmesi gerektiğini aktarmışlardır. Aynı oranda katılımcı ücretlerde iyileşmeye gidilmesini ve fazla mesai ücretlerinin zamanında ödenmesini önermektedir. Katılımcıların yarısı ( $\mathrm{n}=17$ ) sorunları çözme noktasında yöneticilerin çalışanlarla birlikte düzenli toplantılar yapmalarının önemli olduğunu düşündüklerini vurgulamaktadırlar. Üç katılımcı kurum içi sosyal ve kültürel etkinlikler düzenlenmeli önerisinde bulunmuşlardır. Düzenlenmesini istedikleri bu sosyal programlara yöneticilerinin de katılması gerektiğini düşündüklerini eklemişlerdir. Araştırmaya katılanların yaklaşık beşte biri $(n=6)$ iletişim ve çatı̧̧ma çözümüne ilişkin düzenli olarak eğitimler olmalı diye belirtmişlerdir. Bir 
katılımcı ise işe yeni başlayanlara oryantasyon eğitimi olmalı diye önermektedir. Üç katılımcıda herhangi bir önerisi olmadığını ifade etmektedir. Katılımcıların bazılarının görüşleri şu şekildedir;

- "Fiziksel şartlar iyileştirilebilir" (katılımcı 1,7)

- "Çalışan sayısı arttırlabilir, yeterli malzeme olmalı"(katılımcı 6,10)

- "Mesleki sinurlar netleşmeli, görev tanımları net olmalı" (katılımo 17, 21)

- "Fazla mesailer zamanında ödenmeli, ücretlerde iyileşme olmalı" (katıllmo 2,8)

- "Yöneticilerle sorunların çözümü için düzenli toplantılar olmalı" (katılımcl 11, 25, 27, 33, 35)

- "Kurum içi sosyal ve kültürel etkinlikler düzenlenmeli, geziler, müzik etkinlikleri, düzenli kurum içi konferanslar yapılmalı" (katılımoı 19,23,27)

- "Işse yeni başlayanlara oryantasyon eğitimi olmalı" (katılımcı 15)

- "İletişim ve çatışma çözümüne ilişkin eğitimler planlanmalı"(katıllmaı 10,16, 29)

\section{Tartışma ve Sonuç}

Sağlık çalışanlarının üçte birinden fazlası $(\mathrm{n}=14)$ iş doyumunu mutlu - huzurlu olmak şeklinde ifade etmektedir. Katılımcıların dörtte biri $(\mathrm{n}=9)$ iş doyumunu maddi- manevi tatmin olarak düşündüklerini, çalışma grubunu oluşturan personelin üçte biri $(n=12)$ işini severek yapmanın iş doyumu olduğunu vurgulamaktadır. Derin'in (2007) aktardığına göre, Alçıkaya' nın (1999) çalışmasında, mensup olduğu mesleği severek yapmanın iş doyumunu arttırdığını belirlemiştir. Bu sonuç bizim araştırmamızı desteklemektedir (7). Çalışma grubunu oluşturan katılımcıların yarısından fazlası $(\mathrm{n}=21)$ iş doyumunun çalışma ortamının fiziksel şartlarından etkilendiğini düşündüklerini belirtmektedirler. Vural ve ark.'inın yaptığı araştırmaya göre, çalışma ortamı, yönetimin tutumu ile kurumdan ayrılmayı düşünmeme arasında istatistiksel olarak anlamlı ve pozitif bir ilişki saptanmıştır (Vural ve ark., 2012). Bu sonuç çalışmamızın bulguları ile benzerlik göstermektedir. Literatürde iş doyumu ile yaşam doyumu arasında pozitif bir ilişki olduğunu gösteren birçok çalışma olduğu görülmektedir (Alghamdi,2015; Özyer, Irk ve Anaç, 2015; Aşan ve Erenler, 2008; Rode,2004 ). İş yaşamının insan hayatının önemli bir parçası olduğu düşünüldügünde sonuçlar anlaşılabilmektedir. Sağlık çalışanlarının üçte biri (n=12) iş arkadaşlarının iş doyumunu etkilediğini 
ifade etmektedirler. Literatüre bakıldığında, iş arkadaşları ile iyi ilişkiler kurmanın, çalışanların işinden aldığı doyumu arttırdığı yönünde sonuçlara ulaşılan çalışmalara rastlanmaktadır (Judge, Heller, and Mount,2002; Aksu ve Acuner, 2002; Saygılı M, Çelik, 2011). Demir (2016)'in hemşirelerle yaptığ çalışmada iş arkadaşlarıyla iyi ilişkilere sahip olmanın iş doyumunu olumlu yönde etkilediği sonucuna ulaşıldığı görülmektedir (Demir, 2016). Dede ve Çınar (2008) ile Çam ve Yıldırım (2010)'ın yaptıkları çalışmalarda da benzer sonuçlar elde edilmiştir (Dede ve Çınar, 2008; Çam, 2010) Tüm bu sonuçlar araştırma bulgularımızı destekler niteliktedir. Çalışma grubunu oluşturan sağlık çalışanlarının hemen hemen yarısına yakını $(\mathrm{n}=15)$ yöneticilerin motivasyona yönelik tutumlarmm iş doyumunu etkilediğini iletmişlerdir. Göktepe ve Aykal'ın (2012) aktardığına göre; Küçükyılmaz ve arkadaşlarının 2006 yılında yaptıkları çalışmada, iş yerinde meslektaşlardan, yöneticiden, süpervizörden alınan desteğin hemşirelerin iş doyumlarını olumlu yönde etkilediği belirlenmiştir (Göktepe ve Aykal, 2012). İğdelipınar'ın (2013) yöneticilerin etik liderlik davranışlarmın çalışanlarn iş tatminine etkisi konusunda yaptığı çalışmasında ise, etik liderlik davranışlarının katılımcıların iş doyumunu olumlu yönde etkilediği tespit edilmiştir (İğdelipınar, 2013). Çalışma sonuçlarımız literatürdeki verilerle uyum göstermektedir. Çalışmamızda yer alan sekiz katılımcı iş doyumunu ücretin etkilediğini düşündüklerini, dört katılımcı ise rol, görev ve sintrlarm net olmayışını iş doyumunu etkileyebileceğini vurgulamışlardır. Aldahema'nın (2016) yaptı̆̆ çalışmanın sonuçlarına bakıldığında araştırmamızı desteklemediği görülmektedir (Aldehema, 2016). Katılımcıların beşte biri $(\mathrm{n}=7)$ çalışanın ruhsal ve fiziksel bir hastalığını olmasının iş doyumunu etkileyebileceğini ifade etmişlerdir. Tözün ve arkadaşlarının 2008 yılında yaptığı çalışmanın sonuçlarının araştırmamızın sonuçlarından farklı olduğu anlaşılmaktadır (Tözün, 2008). Araştırmamızda yer alan sağlık çalışanlarının yarısından fazlası $(\mathrm{n}=18)$ bel ă̆rısı, yarısına yakını $(\mathrm{n}=14)$ bacak ă̆rısı, dörtte birinden fazlası $(\mathrm{n}=10)$ bacak ve varis ağrısı, beşte biri $(\mathrm{n}=7)$ yorgunluk ve mide şikayetleri olduğunu iletmişlerdir. Türk ve arkadaşlarının yaptığı araştırmada sağlık çalışanlarının \%64'ünde uyku problemleri, \%66'sında denge bozuklukları ve baş ağrısı, \%64'ünde ses ve gürültüye duyarlılık artışı olduğu tespit edilmiş ve bu belirtilerin stresten kaynaklandığı sonucuna ulaşılmıştır (Türk, Eroğlu ve Türk, 2008). Türk ve arkadaşlarının araştırması çalışmamızla paralellik göstermektedir. Çalışmamıza katılan sağlık çalışanlarına çalışma koşullarının ruhsal sağlığı 
nasıl etkilediğine yönelik soru sorulmuş ve katılımcıların yarısı $(\mathrm{n}=17)$ çalışma koşullarının stres oluşturduğuna ilişkin cevap verirken, katılımcıların yaklaşık beşte biri $(\mathrm{n}=6)$ sinirlilik, beş katılımcı ise ruhsal yorgunluk ve buna bağlı uyku problemi olduğunu ifade etmişlerdir. İş yerinde aşırı iş yükünün yarattığ1 stres, fiziksel ve bilişsel yorgunluk ve bitkinlik hali çalışanların yaşam kalitesini ve dolayısıyla yaşamdan sağladığı doyumu olumsuz olarak etkileyebilir. Literatürde farklı araştırmamızın bu bulgusunu destekleyen çalışmalar yer almaktadır (De Cuyper, and Witte, 2006; Goh, Ilies, and Wilson, 2015; Çelik, 2016). Araştırmanın diğer bir bulgusuna göre; katılımcı sağlık çalışanları hizmet verdikleri hastalara yönelik "fazla empati yapmak" sonucu üzüntü yaşadıklarını belirtmişlerdir. Hatipoğlu'nun (2013 ) yaptığı çalışmada, empati eğilim puanının; iş doyumu puanı ile pozitif yönde orta dereceli bir korelasyon gösterdiği bulunmuştur. Hekimin sahip olduğu empati, hekimin iş doyumunu arttırdığı sonucuna ulaşılmıştır (Hatipoğlu, 2013). Bu sonuç çalışmamızın sonucu ile benzerlik göstermemektedir. Araştırmaya katılanların yarısından fazlası $(n=22)$ çalışma koşullarının sosyal yaşamlarını etkilemediğini ifade ederken bunu "profesyonel stnırları korumak lazım", "eve iş götürmem" diye açıklamaktadırlar. Sağlık çalışanlarının üçte biri ise $(n=11)$ sosyal faaliyetlere zaman ayıramadıklarını belirtmişlerdir Literatürde çalışmamıza benzer sonuçlar saptanan çalışmalar bulunmaktadır (Kesgin ve Kublay, 2011; Yıldırım ve Hacıhasanoğlu, 2011). Sağlık çalışanlarının yaklaşık altıda biri $(n=5)$ fiziksel koşullarda iyileşmenin sağlanması gerektiğini ifade etmektedirler. Literatür incelendiğinde yapılan çalışmaların sonuçlarında vardiyalı çalışma, iş kazası riskleri, ağır iş yükü, çalışma şartlarının olumsuz olmasının pek çok sağlık sorununun oluşmasına yol açtığı saptanmıştır (Düzenli, 2015). Bu çalışmaların sonuçları bizim çalışmamızın sonuçları ile benzerlik göstermektedir. Çalışma koşullarında iyileşme kategorisine ilişkin katılımclların yaklaşık üçte biri $(\mathrm{n}=10)$ "görev tanmmları net olmalı" diye belirtmişledir. Sungur'un (2016) farklı meslek üyeleri ile yaptığı araştırmada aile hekimlerinin iş doyumu puanlarının aile sağlığı elemanlarından daha yüksek olduğu belirlenmiş ve aile sağlı̆̆1 elemanlarının iş doyumu puanlarının düşük olmasının nedeninin ise meslek üyelerinin eğitim aldıkları alanlar dışında çalışmak zorunda kalmaları olduğu sonucuna ulaşılmıştır (Sungur, 2016). Bu araştırma sonuçları çalı̧̧mamızın sonuçları ile örtüşmektedir. Araştırmaya katılanların yaklaşık beşte biri $(n=6)$ personel sayısının ve malzeme ihtiyacının giderilmesi gerektiği- 
ni aktarmaktadırlar. Çalışma sonucumuza benzer biçimde hemşirelerle yapılan bir çalışmada hemşireler hastanelerde sarf malzeme, teknik alt yapı, tıbbi araç-gereç konularında yetersizlikler olduğunu ifade etmiş ve iş verimliliği açısından alt yapı ve teknik donanımın önemli olduğunu bildirdikleri saptanmıştır (Göktepe ve Aykal, 2012). Araştırmada yer alan katılımcıların altısı maaş ve ücretlerde iyileşmeye gidilmesini ve fazla mesai ücretlerinin zamanında ödenmesi gerektiğini ifade etmektedirler. Araştırma sonucu dikkate alındığında sağlık çalışanları açısından ücretin iş doyumu için öncelikli bir öneme sahip olduğu görülmektedir. Literatür incelendiğinde çalışmamızdaki sonuçlar ile paralellik gösteren çalışmalara rastlanmaktadır (Çelik, Ünal ve Saruhan, 2012; Özkan, Koçyiğit ve Şen, 2013; Kaya,2009). Katılımcıların yarısı $(\mathrm{n}=17)$ sorunları çözme noktasında yöneticilerin çalışanlarla birlikte düzenli toplantılar yapmalarının önemli olduğunu düşündüklerini vurgulamaktadırlar. Yapılan çalı̧̧malarda da benzer sonuçlara ulaşılmıştır. Yürümezoğlu'nun (2012), İğdelipınar'ın (2013). Meslek üyelerinin iş doyumunu arttırmanın en önemli yollarından biri kurum yöneticilerinin çalışanlarla sıklıkla bir araya gelmesi ve sorunları çözmede karşılıklı fikir alışverişinde bulunulması olduğu sonuçları görülmektedir (Yürümezoğlu, 2012; İğdelipınar, 2013). Altınışık'a göre (1997) yöneticiler, kurum verimliliğini arttırmak için çalışanların algı, beklenti ve gereksinimlerini belirlemeli, çalışanların sorunlarını çözmede aktif rol oynamalıdırlar (Altınışı, 1997). Çankaya ve ark.(2018)'nın eğitim ve araştırma hastanesinde yaptıkları çalışmada yöneticilerin çalışanların iş yükünü yeniden gözden geçirerek, adil bir yönetim anlayışının olduğunu onlara hissettirmelerinin oldukça önemli olduğunu ayrıca bu yönetim biçiminin çalışanların motivasyonlarını arttırdığını bildirmektedir (Çankaya, Gürdal, Tunç ve Orhan, 2018; Kansu, 2016). Çalışmamızda yer alan üç katılımcı kurum içi sosyal ve kültürel etkinlikler düzenlenmeli önerisinde bulunmakta ve düzenlenmesini istedikleri bu etkinliklere yöneticilerin de katılması gerektiğini düşündüklerini eklemektedirler. Çalışanların daha iyi motive olması, birbirlerini daha yakından tanıması, dostça ilişkiler kurması ve örgüt içi kaynaşmayı sağlaması açısından gerçekleştirilen sosyal aktivitelerin önemli olduğu vurgulanmaktadır (Pehlivan, Lafçı, Demiray ve Yaman, 2015). Araştırmamızın bir başka bulgusuna göre katılımcıların yaklaşık beşte biri $(n=6)$ kurum içinde iletişim ve çatışma çözümüne ilişkin düzenli olarak eğitimler olması gerektiğini belirtmektedirler. Yıldırım ve Hacıhasanoğlu'nun (2011) yaptı̆̆ çalışmada kurumlarda 
düzenli olarak iletişim, stres ve çatışma yönetimi gibi konularda eğitimler yapılmasının sağlık personellerinin sorunları ile baş edebilmelerinde kolaylaştırıcı olabileceğini bildirmektedirler (Yıldırım ve Hacıhasanoğlu, 2011). Bir katılımcı ise işe yeni başlayanlara oryantasyon eğitimi olması gerektiğini ifade etmiştir. Yücel ve arkadaşlarının (2013) yaptığı bir çalışmada, tıp öğrencileri ve asistan hekimlere oryantasyon eğitimleri yapıldıktan sonra yaklaşımlarının pozitif yönde ilerleme kaydetmelerinde etkili olduğu saptanmıştır (Yücel, Timlioğlu ve Sağlam, 2013). Kurum kültürünün oluşturulması kadar bir diğer önemli bir konu da, kültürün, kurumun yeni üyelerine aktarılmasıdır. Oryantasyon ve uyum faaliyetleri, kurum kültürünün hem geliştirilmesinde, hem de pekiştirilmesinde büyük önem taşır. Başarılı bir kurumsal yapı, ancak çalışanların değerlerine dayalı bir kültür ile mümkün olabilir (Erdem ve Dikici, 2009). İstanbul'da bir belediyede görev yapan sağlık çalışanlarının iş doyumuna yönelik görüşlerini kendi algıladıkları doğrultuda belirlemek amacıyla yapılan bu çalışmada, katılımcıların kurumun fiziksel şartlarını ve ekip içi iletişimi yetersiz buldukları, yöneticilerin çalışanlarla düzenli toplantılar düzenlemesi gerektiğini düşündükleri, ruhsal sağlıklarının çalışma koşullarından etkilendiği ve buna bağlı stres, sinirlilik, ruhsal yorgunluk ve uyku problemi yaşadıkları, iletişim ve çatışma çözümü konularına ilişkin düzenli olarak eğitim programlarının düzenlenmesi ve kurumda işe yeni başlayanlara yönelik uyum- oryantasyon programlarının planlanması gerektiği gibi sonuçlara ulaşılmıştır. Sonuçlara ilişkin kurum içinde planlamalar yapılması ve farklı örneklem grupları ile çalışmanın tekrarlanması önerilmiştir. 


\title{
EXTENDED ABSTRACT
}

\section{Determination of Job Satisfaction Perceptions of Healthcare Professionals Working in a Municipality: A Qualitative Research}

\author{
Türkan Aşçıŏlu- Mehtap Kızılkaya \\ ISKKi, Aydın Adnan Menderes University
}

Work has a basic function as it is the way of gaining economic gain for individuals to survive. If the employees' attitudes towards the job are positive, then job satisfaction can be mentioned. Job satisfaction is very important as it is related to satisfaction received from the general life. This study was carried out in order to determine the opinions of healthcare professionals working in a municipality in Istanbul on job satisfaction in line with their own perception. The Model of the Research is a single case case study from qualitative research methods. Institutional permission and Ethics Committee approval were obtained for the study (Ethics Committee Approval: Decision No: 88 at the meeting dated 08.11.2017). The study was conducted in accordance with the Helsinki Declaration principles. The population of the study consisted of 47 healthcare workers in the health service unit of the relevant municipality and the sample of 35 healthcare workers who voluntarily accepted to participate in the study. Before starting the data collection process of the research, the participants were informed comprehensively about the purpose of the research. The data of the healthcare professionals who responded positively to this information and accepted to participate in the study voluntarily were obtained by using Sos 'Personal Information Form with Socio-demographic characteristics and" Semi-Structured Question Form ". Personal Information Form; This form consists of 14 questions including gender, age, educational status, marital status, having children, occupation, working year, income level and weekly working time. SemiStructured Question Form; The semi-structured questionnaire consists of 6 open-ended questions in order to reveal the views of healthcare professionals on the concept of job satisfaction, their perceptions of how working conditions affect their physical, mental and social health, and institutional plan- 
ning recommendations. The data were collected between January 1 and February 28, 2018 using a semi-structured interview technique, one of the qualitative research methods. Inductive content analysis technique was used in the analysis of the data obtained. Content analysis is to gather similar data within the framework of certain concepts and themes and to interpret them in a way that the reader can understand. In the analysis of the data, the raw data were read several times by line by line reading technique, each word deemed meaningful through open coding was coded and then thematic coding was done. From codes, categories and then themes were reached. The research results were interpreted by making a literature review. 19 of the participants are women and 16 of them are men. The data obtained through the interview questions were given in the form of themes by transforming them into findings. The healthcare workers, who constitute the study group of the study, were asked what they think about the concept of job satisfaction, and some categories were reached as a result of their answers. More than one third of the healthcare professionals $(n=14)$ expressed their job satisfaction as being happy and peaceful. One fourth of the participants $(n=9)$ stated that they thought job satisfaction as material-moral satisfaction. When asked what the participants' job satisfaction affects, more than half of the healthcare professionals $(n=21)$ stated that they think that job satisfaction is affected by the physical conditions of the work environment. Almost half of the healthcare professionals $(n=15)$ that make up the study group stated that managers' attitudes towards motivation affected their job satisfaction. Four participants emphasized that unclear roles, duties and boundaries can affect job satisfaction. When the healthcare professionals were asked how their working conditions affect their physical health, more than half of them $(n=18)$ stated that they experienced low back pain. While one fifth of the participants $(n=7)$ mentioned fatigue complaints, one participant stated that working conditions can cause stomach complaints. While half of the healthcare workers $(n=17)$ who participated in the study answered the question about how working conditions affect mental health, approximately one fifth of the participants $(n=6)$ stated that nervousness. Five of the healthcare professionals answered as mental fatigue. Two participants reported sleep problems due to mental tension. When asked what are the opinions of healthcare professionals on how their working conditions 
affect social life; One third of the healthcare workers $(n=11)$ stated that they could not spare time for social activities.

- "My time devoted to my family and friends is decreasing, my cultural and artistic activities have decreased" (participant 21)

- "No time for social activities" (participant 17, 28, 30)

- "I have social withdrawal due to fatigue" (participant 18)

The participants were asked their suggestions for a better working environment and some categories were reached as a result of their answers. These categories are improvement in physical conditions, improvement in working conditions, improvement in social planning and improvement in educational activities. Approximately one-fifth $(n=6)$ of the healthcare professionals participating in the study stated that the number of personnel and the need for supplies should be met. At the same rate, it suggests improvement in participant wages and timely payment of overtime wages. Half of the participants $(n=17)$ emphasized that they think it is important for managers to hold regular meetings with employees in solving problems. Three participants suggested that in-house social and cultural events should be organized. They added that they think that their managers should also participate in these social programs that they want to be organized. About onefifth of the participants $(n=6)$ stated that there should be regular training on communication and conflict resolution. In this study, which was conducted in order to determine the views of healthcare professionals working in a municipality in Istanbul in line with their own perception, the participants found the physical conditions of the institution and team communication inadequate, managers thought they should organize regular meetings with employees, their mental health was affected by working conditions and the stress associated with this It was concluded that regular training programs on communication and conflict resolution issues should be organized and adaptation programs should be planned for newcomers in the institution, that they had nervousness, mental fatigue and sleep problems. It was suggested to make in-house planning for the results and to repeat the study with different sample groups. 


\section{Kaynakça / References}

Akbaş, T. (2011). Kuzey Kıbrıs Türk Cumhuriyeti deolet hastanelerinde çalışan hemşirelerin iş doyumu düzeyinin belirlenmesi. Yüksek Lisans Tezi, Yakın Doğu Üniversitesi Sağlık Bilimleri Enstitüsü, Hemşirelik Programı.

Aksu, G., Acuner, A.M. ve Tabak, R.S. (2002). Sağlık Bakanlığı Merkez ve taşra teşkilatı yöneticilerinin iş doyumuna yönelik bir araştırma: Ankara örneği. Ankara Üniversitesi Top Fakültesi Mecmuası, 55(4), 271-82.

Aldehema, M.A. (2016). Sağhlk çalışanlarnnın iş doyumunu etkileyen bireysel ve örgütsel faktörler ve maliyetleri. Dokuz Eylül Üniversitesi Sosyal Bilimler Enstitüsü, İşletme Anabilim Dalı; İzmir.

Alghamdi, F.S., (2015). Another look at job and life satisfaction among employees: Evidence from a developing country. American Journal Of Industrial And Business Management, 5, 11-19.

Altınışı, S. (1997). Örgütsel etkililikte iş doyumunun etkisi. Kuram ve Uygulamada Ĕgitim Yönetimi Dergisi, 3(2), 135-153.

Aşan, Ö. ve Erenler, E. (2018). İş tatmini ve yaşam tatmini ilişkisi. Süleyman Demirel Üniversitesi İktisadi ve İdari Bilimler Fakültesi Dergisi, 13 (2), 203-216.

Aytekin, A. ve Fatma, Y.K. (2014). Yenidoğan yoğunbakım kliniği'nde çalışan hemşirelerde iş doyumu ve etkileyen faktörler. Izmir Behçet Uz Çocuk Hast. Dergisi, 4(1), 51-58.

Çam, O., ve Yıldırım, S. (2010). Hemşirelerde iş doyumu ve etkileyen faktörler. Türkiye Klinikler, 2(1), 64-70.

Çankaya, S., Gürdal, O., Tunç, T. ,Orhan, H. (2018). Eğitim-araştırma hastanelerinde çalışanların iş doyumu, örgütsel bağlllık ve tükenmişlik düzeyleri arasındaki ilişkilerin yapısal eşitlik modeli ile incelenmesi: Ordu İi örneği. SDÜ Tip Fak Derg. 25(4), 436-449.

Çelik, M. (2016). Tükenmişlik yaşam doyumu ve iş yükü ilişkisi: Denizli'de faaliyet gösteren muhasebe meslek mensupları üzerinde bir araştırma. Süleyman Demirel Üniversitesi İktisadi ve İdari Bilimler Fakültesi Dergisi, 21(4), 1139-1152.

Çelik, S., Ünal, Ü., Saruhan, S. (2012). Cerrahi kliniklerde çalışan hemşirelerin mesleki profesyonelliklerinin değerlendirilmesi. İ.Ü.F.N. Hem. Dergisi, 20(3), 193-199.

De Cuyper, N. ve De Witte, H. (2006). Autonomy and workload among temporary workers: Their effects on job satisfaction, organizational commitment, life satisfaction, and self-rated performance. International Journal of Stress Management, 13(4), 441-459. 
Dede, M. ve Çınar, S. (2008). Dahiliye yoğun bakım hemşirelerinin karşılaştıkları güçlükler ve iş doyumlarının belirlenmesi. Maltepe Üniversitesi Hemşirelik Bilim ve Sanatı Dergisi, 1(1), 3-14.

Demir, S. (2016). Hemşirelerde iş doyumuna etki eden faktörlerin incelenmesi. Tezsiz Yüksek Lisans Bitirme Projesi İzmir Katip Çelebi Üniversitesi, Sosyal Bilimler Enstitüsü, Sağlık Kuruluşları Yöneticiliği Anabilim Dalı; İzmir

Derin, N. (2007). Deolet hastanelerinde çalışan sağllk personelinin iş doyum düzeyleri ve etkileyen faktörler. Eskişehir Osmangazi Üniversitesi, Sağlık Bilimleri Enstitüsü Yüksek Lisans Tezi; Eskişehir.

Düzenli, Z. (2015). Hemşirelerde rol çatışması ve rol belirsizliğinin iş doyumuna etkisi. Atatürk Üniversitesi Sağlık Bilimleri Enstitüsü, Psikiyatri Hemşireliği Anabilim Dalı Yüksek Lisans Tezi;.

Düzova, S. (2015). 112 acil serois hizmetlerinde çalşan personelin iş doyumu: Ankara İli örneği. Yüksek Lisans Tezi, Atllım Üniversitesi Sosyal Bilimler Enstitüsü, İşletme Anabilim Dalı Sağlık Kuruluşları Yöneticiliği, Ankara

Eğinli, A.T. (2009). Çalışanlarda iş doyumu: Kamu ve özel sektör çalışanların iş doyumuna yönelik bir araştırma. Atatürk Üniversitesi İktisadi ve İdari Bilimler Dergisi, 23(3), 35-52.

Erdem, O. ve Dikici, A. M. (2009). Liderlik ve kurum kültürü etkileşimi. Elektronik Sosyal Bilimler Dergisi, 8(29), 198-213.

Goh, Z., Ilies, R. ve Wilson, S.K. (2015). Supportive supervisors improve employees daily lives: The role supervisors play in the impact of daily workload on life satisfaction via work-family conflict. Journal of Vocational Behavior, 89, 65-73.

Göktepe, N. ve Aykal, Ü. (2012). Hemşirelerin verimliliğe ilişkin tutumları ile hastanelerin örgütsel ve yönetsel yapılarına ilişkin özelliklerinin karşılaştırılması. Hemşirelikte Ĕ̆itim ve Araştırma Dergisi, 9(1), 16-22.

Göktepe, N. ve Aykal, Ü. (2012). Hemşirelerin verimliliğe ilişkin tutumları ile hastanelerin örgütsel ve yönetsel yapılarına ilişkin özelliklerinin karşıaştırılması. Hemşirelikte Ĕ̆itim ve Araştırma Dergisi, 9(1), 16-22.

Hatipoğlu, C. (2013). Hekimlerde empati, iş doyumu işs stresi düzeyleri ve birbirleri ile ilişkisi. Pamukkale Üniversitesi Tıp Fakültesi Halk Sağlığı Anabilim Dalı; Denizli.

İğdelipınar, N. (2013). Çalışanlarn iş tatmin düzeylerine yöneticilerin etik liderlik davranışlarmın etkisi. Yüksek Lisans Tezi, Bahçeşehir Üniversitesi Sosyal Bilimler Enstitüsü, İnsan Kaynakları Yönetimi; İstanbul.

Judge, T.A., Heller, D., ve Mount, M.K. (2002). Five-Factor model of personality and job satisfaction: A meta-analysis. Journal of Applied Psychology, 87(3): 530. 
Kansu, N. (2016). Sağlık kurumlarndaki lider (yönetici) tutumlarmın çalışanların örgütsel bağhlı̆̆ı üzerine etkisi. Beykent Üniversitesi Sosyal Bilimler Enstitüsü, İşletme Yönetimi Anabilim Dalı Hastane ve Sağlık Kurumları Yönetimi Bilim Dall; İstanbul,.

Kaya, B. (2009). Ebelerin iş doyumu ve tükenmişlik durumlarm etkileyen faktörler. Yüksek Lisans Tezi, Adnan Menderes Üniversitesi Sağlık Bilimleri Enstitüsü, Kadın Sağlığı ve Hastalıkları Hemşireliği Anabilim Dalı

Kaya, T.N. ve Bilgin S. (2015). Çankırı İl merkezinde birinci basmak sağlık kuruluşlarında çalışan ebe ve hemşirelerde iş doyumu düzeyi ve etkileyen faktörlerin değerlendirilmesi. Hacettepe Üniversitesi Sağlık Bilimleri Dergisi, 1(1), 124.

Kesgin, M.T. ve Kublay, G. (2011). Özel bir hastanede çalışan hemşirelerin yaşam alışkanlıkları ve çalışma koşullarından kaynaklı sağlık sorunlarının değerlendirilmesi. Să̆lık Bilimleri Fakültesi Hemşirelik Dergisi, 41-49.

Özkan, Ö., Koçyiğit, Z. Ve Şen, Ü. (2013). Özel hastanelerde çalışan hemşirelerin algılanan iş ve gelir güvencesizliği ile çalışma koşulları. Cumhuriyet Hemşirelik Dergisi, 2(1), 15-25.

Özyer, K., Irk, E. ve Anaç, S. (2015). İş tatmini ve yaşam tatmini ilişkisinde iş arkadaşlığının aracılık rolü. C.Ü. İktisadi ve İdari Bilimler Dergisi, 16 (1), 261-278.

Pehlivan, S., Lafçı, D., Demiray, G. ve Yaman, M. (2015). Cerrahi kliniğinde çalışan hemşirelerin örgüt kültürünü alglamaları. Sağllk ve Hemşirelik Yönetim Dergisi, 2(1), 12-24.

Rode, J.C. (2004). Job satisfaction and life satisfaction revisited: A longitudinal test of an integrated model. Human Relations, 57(9), 1205-1230.

Saygılı, M. ve Çelik, Y. (2011). Hastane çalışanlarının çalışma ortamlarına ilişkin algıları ile iş doyumu düzeyleri arasındaki ilişkinin değerlendirilmesi. $\mathrm{Ha}$ cettepe Sağ̆lk İdaresi Dergisi, 14(1), 40-71.

Sungur, T. (2016). Aile hekimliği personelinin iş doyumu: İstanbul Esenler İlçesi örneği. Beykent Üniversitesi Sosyal Bilimler Enstitüsü, İşletme Yönetimi Ana Bilim Dall.

Taş, A. ve Önder, E. (2010). Yöneticilerin liderlik davranışlarının personel iş doyumuna etkisi. Elektronik Sosyal Bilimler Dergisi, 9(32), 1730.

Toker, İ. (2013). Acil tıp uzmanlık öğrencilerinde iş doyumu ve tükenmişlik düzeylerini etkileyen faktörler. Uzmanlık Tezi, Mersin Üniversitesi Tıp Fakültesi, Acil Tıp Anabilim Dal. 
Tözün, M., Çulhacl, A., ve Ünsal, A. (2008). Aile hekimliği sisteminde birinci basamak sağlık kurumlarında çalışan hekimlerin iş doyumu. TAF Prev Med Bull, 7(5).

Türk, K., Eroğlu, C., veTürk, D. (2008). TC. devlet hastanelerindeki çalışma koşullarunın stres üzerine etkilerini ölçmeye yönelik bir araştırma: Geyve Devlet Hastanesi örneği. Uluslararası İnsan Bilimleri Dergisi, 5(1), 1303-5134.

Vural, F., Dura, A.A., Fil, Ş., Çiftçi, S., Torun, S.D. ve Patan, R. (2012). Sağlık çalışanlarında memnuniyet, kurumda kalma ve örgütsel bağlllı̆ga etki eden faktörler. Balıesir Să̆glk Bilimleri Dergisi, 1(3), 137-144.

Yıldırım, A. ve Hacıhasanoğlu, R. (2011). Sağlık çalışanlarında yaşam kalitesi ve etkileyen değişkenler. Psikiyatri Hemşireliği Dergisi, 2(2), 61-68.

Yıldırım, A. ve Şimşek, H. (2008). Sosyal bilimlerde nitel araştırma yöntemleri. (6. Baskı). Ankara: Tipkı Basım.

Yücel, D., Timlioğlu, S. ve Sağlam, Z.A. (2013). Asistan hekim oryantasyon (uyum) eğitimlerinin etkinliğinin ölçülmesi. Göztepe Tip Dergisi, 28(3), 120-124.

Yürümezoğlu, H.A. (2012). Kanta dayalı hemşirelik yönetimi uygulamalarnnı hemşire iş doyumu örgütsel bağhllk ve işten ayrlma niyeti üzerine etkisi. Dokuz Eylül Üniversitesi Sağlık Bilimleri Enstitüsü; İzmir.

\section{Kaynakça Bilgisi / Citation Information}

Aşçığlu, T. ve Kızılkaya, M. (2021). Bir belediyede görev yapan sağlık çalışanlarının iş doyumu algılarının belirlenmesi: Nitel bir araştırma. OPUS-Uluslararası Toplum Araştırmaları Dergisi, 17(34), 1204-1223. DOI: 10.26466/opus.789148 